\title{
Application of Passive Wireless RFID Asset Management in Warehousing of Cross-Border E-Commerce Enterprises
}

\author{
Mao Hehua (iD \\ Shazhou Professional Institute of Technology, Zhangjiagang, Jiangsu 215600, China \\ Correspondence should be addressed to Mao Hehua; maohehua@szit.edu.cn
}

Received 13 October 2021; Revised 29 November 2021; Accepted 2 December 2021; Published 31 December 2021

Academic Editor: Guolong Shi

Copyright ( 2021 Mao Hehua. This is an open access article distributed under the Creative Commons Attribution License, which permits unrestricted use, distribution, and reproduction in any medium, provided the original work is properly cited.

\begin{abstract}
As an important part of modern logistics, warehousing provides a guarantee for the sustainable stability of enterprises, so as to realize the economy of enterprise production and transportation and so as to realize the economy of enterprise production and transportation. With the advent of the information age, the traditional logistics management model has been difficult to adapt to the current increasingly fierce market competition environment. In the management of cross-border e-commerce enterprises, warehouse management must establish a systematic and information-based logistics warehouse management system to improve the level of logistics management. Passive wireless RFID asset management provides a new idea for the construction of warehousing management system of cross-border e-commerce enterprises. Through the application of RFID technology, the warehousing design scheme and process of cross-border e-commerce enterprises can be optimized and controlled to the greatest extent, so as to strengthen the optimization and integration of supply chain and improve the market competitiveness of logistics enterprises. Based on the wireless passive RFID asset management technology, this paper analyses the construction and optimization of the logistics warehouse management system of cross-border e-commerce enterprises. The simulation results show that after the application of wireless passive RFID asset management technology, the warehouse operation efficiency of cross-border e-commerce enterprises is improved, the employee utilization rate is relatively reduced, and at the same time, it can also save a lot of manpower and reduce the labour cost.
\end{abstract}

\section{Introduction}

At present, the increasingly competitive global market makes the life cycle of new products shorter and shorter, and customer expectations are also rising, forcing enterprises to focus on the competition to improve the efficiency of the supply chain. At the same time, the rapid development of communication and computer technology urgently requires enterprises to improve their supply chain management level [1]. To promote the continuous upgrading of supply chain and management technology, warehouse management has always been a key link in the logistics system. At present, the scientific and technological utilization level of supply chain and management technology of most enterprises is generally low. Especially in the warehouse management, this link frequently shows a variety of inefficient and uncoordinated phenomena, low efficiency, and high error of warehouse information processing; wrong and missing pick-up occur frequently, enterprise logistics has high storage space and high cost, the supervision ability of goods in transit and dump is insufficient, and the efficiency of sporting goods is low [2]. Lack of scientific and technical guidance, warehouse management is disconnected from other links in the supply chain. Today, with the success of efficiency and service, the low efficiency of warehousing and logistics seriously restricts the development of enterprises. Enterprises are urgently required to take science and technology as the guidance and practical problems as the starting point. Improve the level of warehouse management, improve the weak links of warehouse, reduce inventory costs, and improve the reflection efficiency of supply chain [3]. Optimize the supply and demand mechanism and tap the potential profits of the supply chain. Warehousing not only restricts the development of the whole supply chain but also affects the whole logistics system. Warehouse management provides necessary conditions for the successful 
completion of product reproduction. The new requirement of supply chain for warehousing is to be able to handle goods accurately and quickly and to respond accurately and quickly to some special needs of production enterprises [4]. At the same time, enterprises also need warehousing to provide corresponding value-added services in the logistics supply chain.

As a new technology in logistics storage, RFID technology is widely used in the fields of transportation, industrial engineering, supermarket retail, item management, and so on. In the field of logistics warehousing, with the combination of RFID technology and bar code technology [5], bar code technology is adopted in commodity personality to distinguish commodities and store basic information such as goods brand and performance, while RFID technology is adopted in commodity batch management to carry out catalo batch management of stored goods, and electronic labels are introduced into the batch goods management platform. It is used to enter the catalo information of batch products, such as origin, quality, quantity, destination, storage conditions, storage requirements, and other detailed information [6]. The reader is used to read and write barcode information and electronic label information and upload them to the computer. The data is recorded, analysed, saved, and uploaded to the cloud through the computer information system, so as to complete the recording of goods inventory information [7]. Then, the records are transmitted to the relevant processing software to analyse the storage information such as inventory, order batch, and order cycle, so as to complete the inventory management of the warehouse. At the same time, the upstream supplier is remotely controlled to provide it with delivery and distribution information, so as to complete the information management of the warehouse inventory [8].

Based on the rapid development of cross-border ecommerce industry, the rapid rise of logistics storage demand, and the relatively backward technology and level of storage asset management, this paper studies RFID technology and its system and tries to solve the problems of low efficiency and high cost in storage management. The warehouse has long operation cycle, slow speed, sluggish data collection, slow emergency response, and other problems. By analysing the characteristics of RFID technology, the existing technologies of logistics warehouse management and the existing problems of logistics warehouse management, and combined with the background of logistics industry and logistics warehouse field, this paper discusses the improvement of the efficiency of logistics warehouse management after the introduction of RFID technology. Through the analysis of simulation results, it is proved that after the application of wireless passive RFID asset management technology, the warehousing operation efficiency of cross-border e-commerce enterprises is improved, the employee utilization rate is relatively reduced, at the same time, it can also save a lot of manpower and reduce the labour cost.

The specific chapters of this paper are arranged as follows: Section 1 introduction mainly gives the background of this topic and the current situation of RFID technology at home and abroad. Section 2 discusses the related work, and Section 3 analyses the system composition, working principle, and process of RFID technology. Section 4 constructs the warehousing system based on wireless passive RFID asset management. Section 5 optimizes the warehousing management process of RFID according to the characteristics of cross-border e-commerce enterprises. Section 6 analyses and discusses the optimization results. Section 7 summarizes the full text and looks forward to further research directions.

\section{Related Work}

Warehousing is an important part of logistics. Information management can effectively improve its operation efficiency, but the traditional warehouse management system and a large number of manual operations will make the enterprise management process extremely complex and the cost is very high. RFID, as an increasingly widely used RFID technology, can effectively combine it with the warehouse management system, which can solve the problems of information input, information output, business process control, and tracking of various business operation materials in the supply chain, greatly reduce the production errors caused by changes in time and location in terms of material flow, business flow, information, and capital, and improve the efficiency of warehouse management [9]. The development of warehousing industry started earlier and developed relatively mature in foreign countries. Foreign scholars have a comprehensive research on warehouse management. RFID is the most recognized warehouse management system application technology at present. In recent years, there has been a lot of progress in the application research of RFID, some of which are as follows.

Relevant scholars' early research on warehouse management mainly focused on operation efficiency and warehouse location optimization. With the emergence of high and new technologies such as RFID, a large number of scholars participated in the research on the introduction of RFID technology in warehouse management. They improved the level of warehouse management by studying the application scheme of RFID Technology. However, the research of foreign scholars on warehouse management is mainly aimed at the popular warehouse management [10]. Few literatures can mix RFID science with the warehouse administration traits of cross-border e-commerce corporations to learn about the software scheme of RFID in the warehouse of cross-border e-commerce enterprises. With the emergence of RFID technology, some pupils study from the utility journey of RFID in overseas storage and follow RFID technological know-how to storage management. Using RFID technology and database technology, a food warehouse management system is designed, and its advantages and disadvantages are analysed. Based on the analysis of the security problems faced by warehousing, this paper gives the solution of RFID technology applied to logistics warehousing security, so as to further ensure the security of information and improve the quality of automatic management. In view of the low degree of enterprise informatization and backward 
technology development, combined with the application experience of RFID at home and abroad, this paper puts forward the corresponding solutions, designs the application scheme of RFID technology in industry warehousing, and applies RFID technology to optimize the proportion. Foreign pupils utilized the simulation approach to the research of warehouse management. They hooked up the warehouse procedure mannequin from the targets of design, price, and efficiency and acquired exceptional lookup outcomes [11]. As a research method of warehouse management, process simulation can not only objectively evaluate the operation of warehouse but also put forward a reasonable scheme for process optimization.

Relevant scholars believe that simulation can provide a platform for complex system design and maximize the benefits of different equipment and personnel in the system. Taking EMU simulation analysis as an example, this paper expounds the system design based on collaborative simulation [12]. This paper applies simulation science to product development, places ahead a product sketch and improvement framework based totally on simulation, summarizes the well-known steps of logistics device simulation method, and offers an empirical analysis. Many other scholars apply simulation technology to warehouse management, apply simulation model to the implementation steps of warehouse design, summarize the adaptability of simulation technology, and explain the evaluation role of simulation in warehouse design through examples. Through the literature review of warehouse process simulation research, it can be found that the use of simulation means can not only better analyse and evaluate the level of warehouse management but also find out the weak links in warehouse management and optimize it [13]. According to the warehouse administration traits of cross-border e-commerce enterprises, RFID science is brought into the warehouse administration process, the software mode of RFID science in the warehouse of cross-border e-commerce companies is studied, the warehouse operation process of cross-border e-commerce enterprises is transformed, and the warehouse process is modelled and simulated by software; on the one hand, analyse and evaluate the improvement degree of RFID technology to the warehousing management efficiency of crossborder e-commerce enterprises [14]. On the other hand, further optimize the warehousing operation process by studying the RFID operation process model to ensure the rational and efficient use of RFID technology.

\section{Related Technologies of RFID}

3.1. Composition and Working Principle of RFID System. RFID is a wireless identification technology of noncontact two-way data transmission. It transmits data between readers and electronic tags by radio frequency, so as to realize rapid identification and data exchange. The traditional RFID system consists of six parts, including processor, transmitter, antenna, receiver, tag, and middleware bridging RFID hardware and enterprise applications. The reader is fixed at the designated position to detect the goods within its range; labels cannot only be attached to independently placed goods. It can also be attached to containers or custom pallets [15]. By installing a corresponding reader near the tag, the tag can transmit data through radio frequency to monitor the geographical location, basic information, and physical environment of goods.

Antenna is a very important component in RFID system. Its function is to transmit RF signals. This will dock the tag with the reader. The reader can connect one or more antennas, that is, the reader can connect data with multiple tags, but only one antenna can be activated each time the tag is read. The shape and size of the antenna will vary according to the difference of working frequency and function [16]. The reader can read RFID tags with different frequencies by activating different antennas. The reader is called interrogator because its job is to actively ask for identification information from the label within the reading range. The common hand-held reader integrates intelligent terminal equipment, RFID reader, and antenna to realize mobile reading, which provides great convenience for users. The working frequency range of RFID system is very wide. The matching problem between label chip and large line will become very complex. But at the same time, it can also adapt to the changeable environment according to its different working frequency.

RFID tag is composed of micro antenna, chip, coupling element, or battery. Generally, RFID tags are divided into passive tags and active tags according to different ways of sending signals. The biggest difference in structure is whether there is a battery. Of course, its working principle is also different. The passive tag depends on the energy address of the inductive porcelain when it receives the RF signal sent by the reader within the identification range of the RFID reader. Then, passively transmit the EPC code in the chip. When the active tag enters the recognition range of the reader, it actively sends its electronically encoded signal.

3.2. Workflow of RFID System. According to different data storage methods, RF tags can be divided into three types: programmable read-only storage, programmable randomaccess storage, and static random storage. The general RFID system mainly adopts electrically writable programmable read-only storage. The disadvantage of this method is that the power consumption in the writing process is very large. However, its service life can reach more than 100000 times. When the requirements are high, electrically erasable programmable random access will be adopted. The power consumption written in this storage mode is only $1 / 100$ of that of programmable read-only storage. The writing time is also $1 / 1000$ of that of this method, which belongs to nonvolatile memory, but the memory has high manufacturing cost and small production scale, so it has not been widely used so far. Static random-access memory is suitable for microwave system because it can write data quickly, but it needs auxiliary battery power to save data. Its application range is limited because of its high cost. The general workflow of RFID system is as follows: first, RFID reader will send RF signal with instructions to RFID electronic tag through antenna. After the RF signal is received by RFID electronic tag, it will 


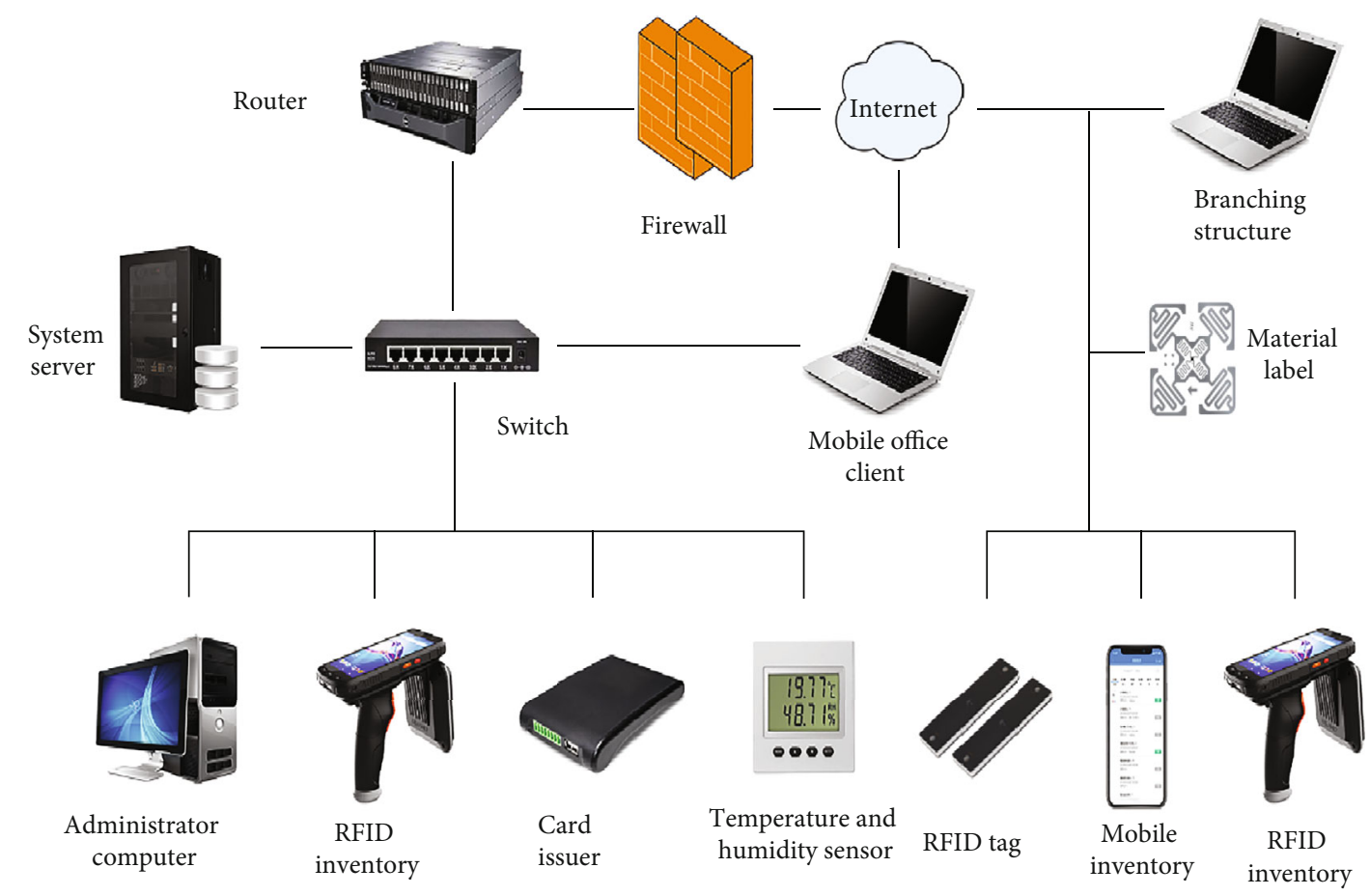

FIgURE 1: Workflow of RFID system.

be activated by induced current generated by antenna and generate energy. RFID electronic tag will establish power supply through this energy. After the RFID tag is powered on, it will routinely be given the inquiry guidance of the RFID reader and enter the different response kingdom [17]. Then, the stored data information is converted into RF signal and fed back to RFID reader. Second, after receiving the RF signal sent from the RFID tag, the RFID reader will decode the RF signal and then transmit the decoded data to the application software system for data analysis and processing. Finally, the application software system will output different data processing for different data information according to the logical algorithm and then send corresponding operation instructions to the RFID reader through the middleware to instruct the RFID reader to perform system operation and end the workflow of the RFID system. The workflow of RFID system is shown in Figure 1.

\section{Construction of Asset Management Warehouse System Based on Passive Wireless RFID}

4.1. Design of Overall Architecture. According to the threetier architecture of perception layer, network layer, and application layer proposed by the Internet of things, we constructed the overall architecture of the third-party logistics supply chain based on the Internet of things technology, as shown in Figure 2. Of which, (1) the main function of the sensing layer is to build the infrastructure of third-party logistics and provide hardware level support for the upper information system through the use of relevant components, such as RFID readers, antennas, tags, sensors, smart tags integrating RFID and sensor chips, computer hardware servers, and network equipment. (2) The main functions of the network layer are the acquisition, transmission, processing, and collaboration of relevant logistics information. It is based on hardware. The main functional modules are RFID middleware and related extensions, including data acquisition, information writing, collision detection, information filtering, and data fusion; the technologies involved include logistics information acquisition technology, logistics information transmission technology, and logistics information control technology. (3) The application layer mainly refers to the application system integrating a variety of logistics information. It is built on the basis of RFID middleware and completes a variety of management functions, including order, transportation, warehousing, and distribution. It can provide targeted services according to the personalized needs of specific users. The key applications of the application layer can be divided into enterprise internal systems according to their openness and open to public platforms such as governments, transporters, agents, and customers through EDI interface.

\section{Overall Architecture of RFID System}

5.1. Process Design. Optimize the process by adding internet of things technology in the process of logistics and warehousing; at the same time, by integrating sensing technology with traditional middleware, enterprises can integrate with sensing technology in all aspects. The specific process is as follows: (1) goods warehousing. When the warehouse receives goods, it can use the label printer to print the preallocated relevant information into electronic labels before warehousing, and then when entering the warehouse door, 


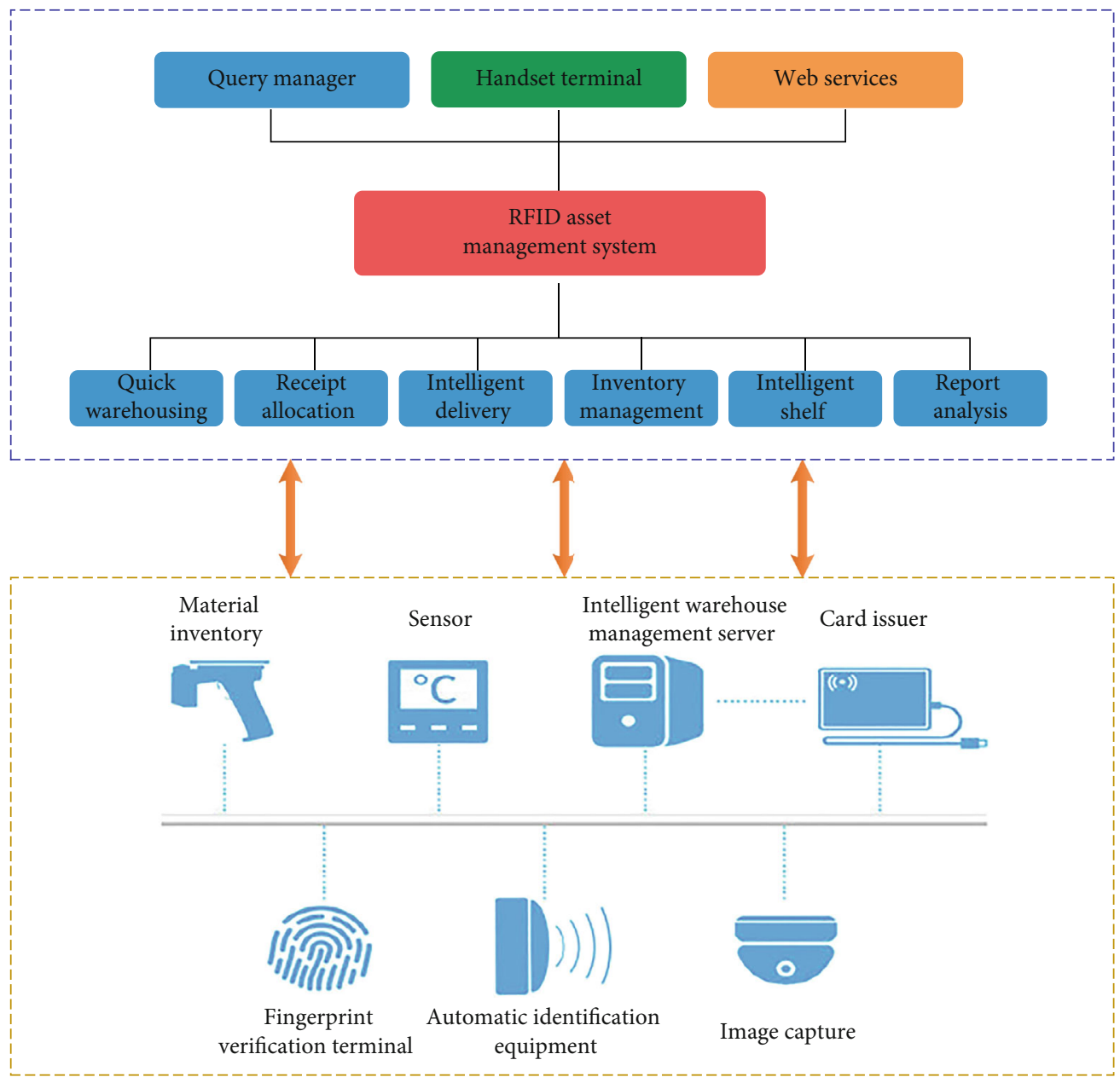

FIgURE 2: Optimized warehousing process.

there is RFID reading and writing equipment installed on the door to complete the warehouse warehousing process. (2) Guide the goods to be put on the shelf. After the goods are put into storage, if RFID tags are pasted, the operator can scan the tags to obtain the storage location information of the goods and guide and confirm the storage location of the goods by reading the RFID tags deployed in the shelf area to complete the rapid putting on the shelf. (3) Goods inventory: through the handheld RFID device, customers can quickly complete the inventory of goods in the designated area without unpacking and reduce the workload. The above is the application of RFID technology in the warehousing and storage process of goods, and the following is the improvement of RFID technology in the process of goods delivery: (4) Customer-driven process initiation: the logistics customer order system receives the customer order and initiates the logistics transportation process. The system automatically specifies the picking warehouse and picking line and notifies the relevant warehouse to replenish [18]. Then, allocate vehicles according to the transportation line to generate the delivery order. (5) Picking process: the warehouse completes the delivery order handover with the customer order management system and initiates the picking process. For goods that have not printed labels in the ware- housing process, the labels shall be printed and pasted before picking. According to specific needs, information such as order number and estimated weight of goods can be written in the labels. If the labels are printed and pasted before storage, intelligent search and picking can be realized during the picking process. (6) Goods outbound: after picking, the goods enter the warehouse gate for outbound process. In the outbound process, the goods can be weighed and verified, that is, the RFID reading process and goods information can be verified by comparing the estimated weight with the actual weight in the RFID information. At the same time, the GPS module with RFID tag can also be put into the goods and finished in the outbound process The GPS module is automatically bound with the goods to facilitate the tracking in transit in the next step.

5.2. RFID Read Verification Link. By using RFID tags many times in the logistics process, the purpose of indirectly reducing the use cost of RFID tags can be achieved. Similarly, appropriate modifications to the logistics process can also shield the problem of low reading rate of RFID hardware equipment and improve the reliability of the whole system. This section checks the reading effect by adding electronic weighing equipment in the system 


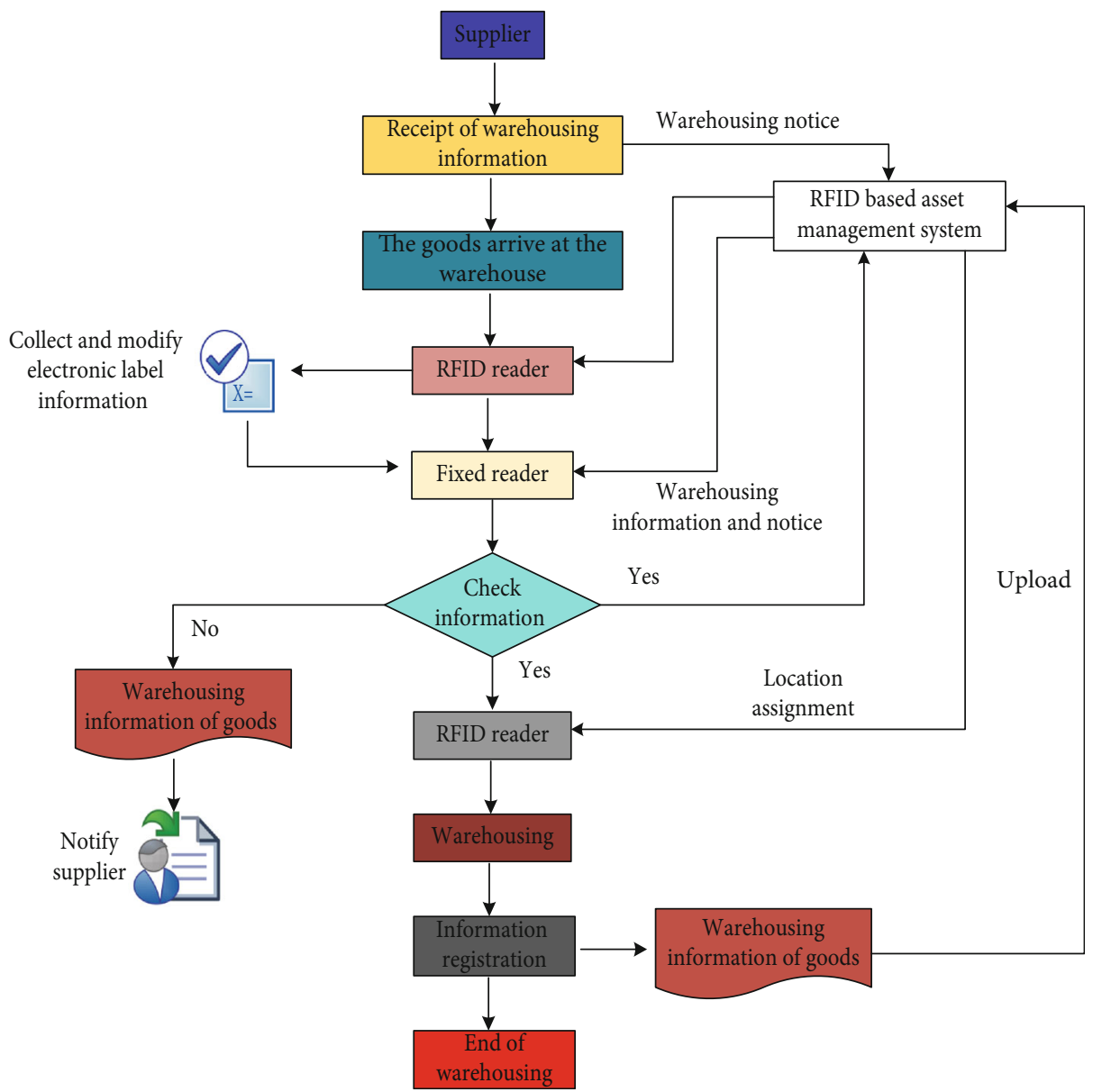

FIGURE 3: Optimized warehousing process.

delivery phase. If the reading is completed, the system will deliver the goods smoothly. If the reading fails, an alarm message will be sent to prompt the operator to carry out the delivery operation again, by adding an electronic scale in the label area and assisting a certain software process, determine whether the read weight is consistent with the estimated weight, so as to know whether all labels have been read. Finally, the weighing verification of RFID reading link is realized.

The specific process is as follows: (1) when printing the label, the estimated weight information of the goods is written into the RFID tag. The advantage of this is that in the weighing link, and the system middleware does not need to query the background database, so as to speed up the progress of the verification link. For the estimated information, the vast majority of logistics management systems currently support the evaluation of cargo information, which is not technically difficult to achieve. (2) During delivery, the goods with RFID tags are pushed to the RFID reading area equipped with electronic scales. The RFID middleware reads the information in the tags, calculates the estimated weight in the information, and obtains the actual weight of the electronic scales for comparison. If the error is within the acceptable range, it is considered that this is a successful reading. Otherwise, the task reading fails, start the alarm and remind the operator to reissue the warehouse for verification [17].

\section{Optimization of Warehousing Process Based on RFID Asset Management}

6.1. Standardization of Warehousing Operation Process. The warehousing characteristics of the company's goods are large volume and strong liquidity. Therefore, the first problem to be solved is to improve the warehousing speed of goods. The second is to ensure the accuracy of cargo information. The process operation after the application of RFID technology shall minimize the operation of warehouse staff on goods to ensure that goods are not subject to accidental physical damage. In order to optimize the warehousing business process of the company, the company needs to add some RFID technology applications on the basis of the previous traditional warehousing management warehousing business process $[18,19]$. The company applied RFID technology to optimize the warehousing process design. Simplify the warehousing process. At the same time, due to the reduction of human use, the risk of manual errors is also reduced, the accuracy of goods data is guaranteed, and the warehousing efficiency is improved on the whole. The optimized warehousing process is shown in Figure 3. 


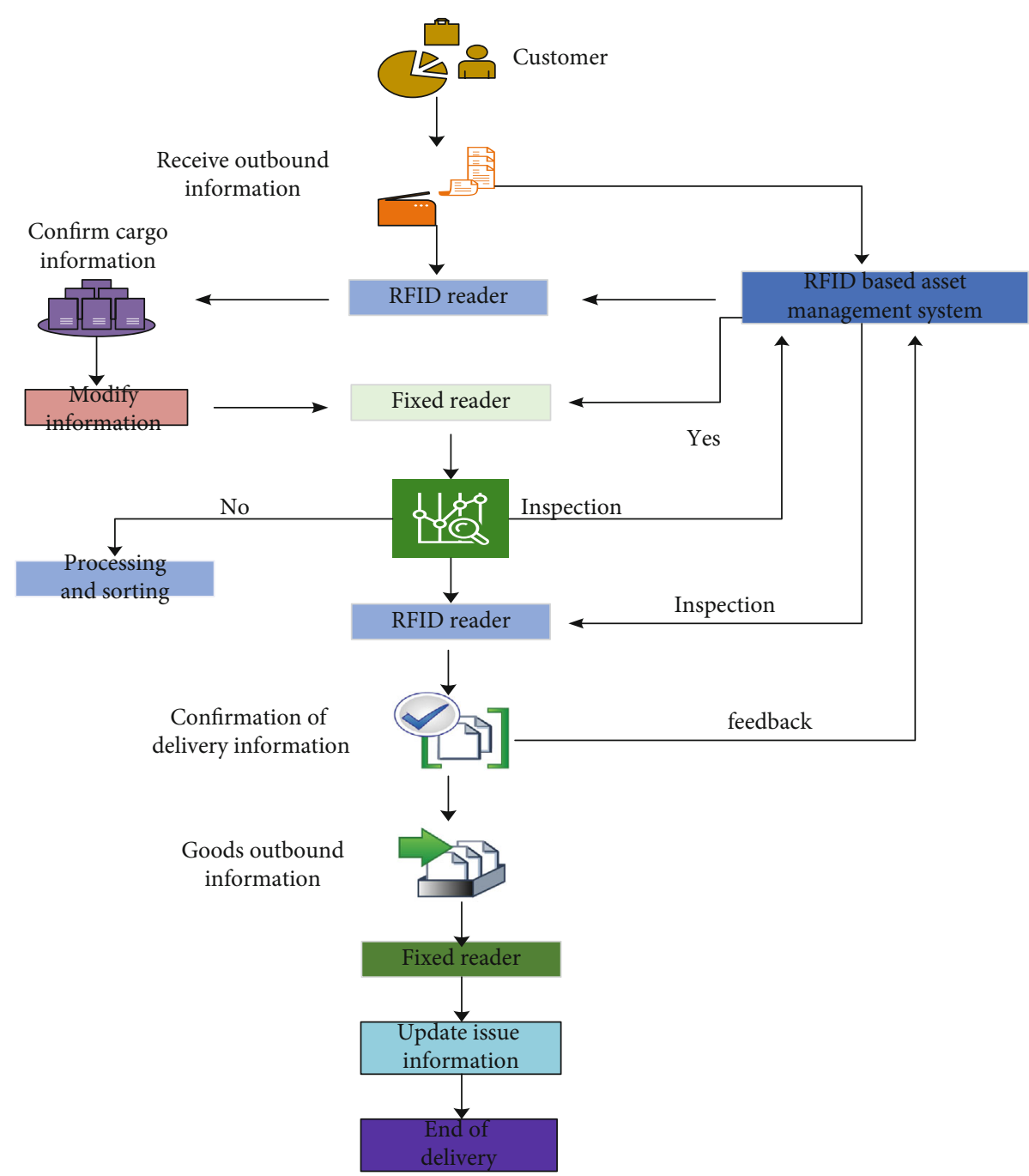

FIGURE 4: Optimized delivery process.

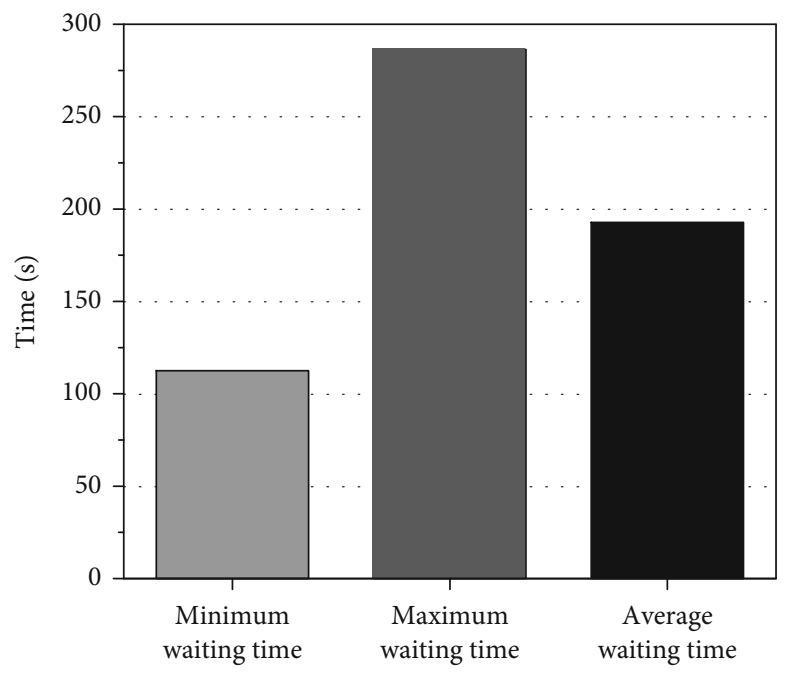

Waiting time for goods warehousing

(a) Waiting time for goods warehousing

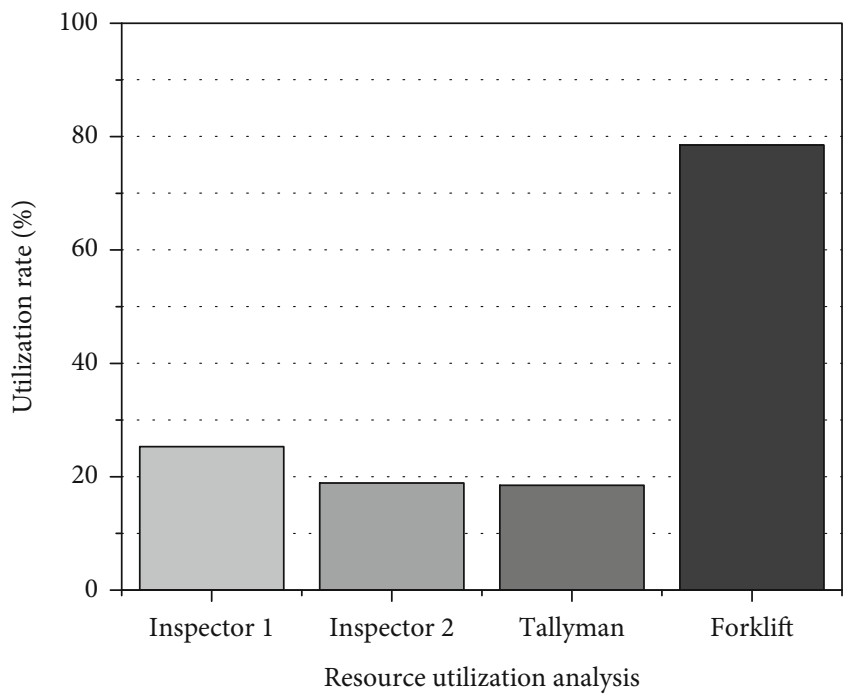

(b) Resource utilization analysis

FIGURE 5: Simulation operation statistics results of warehousing process. 


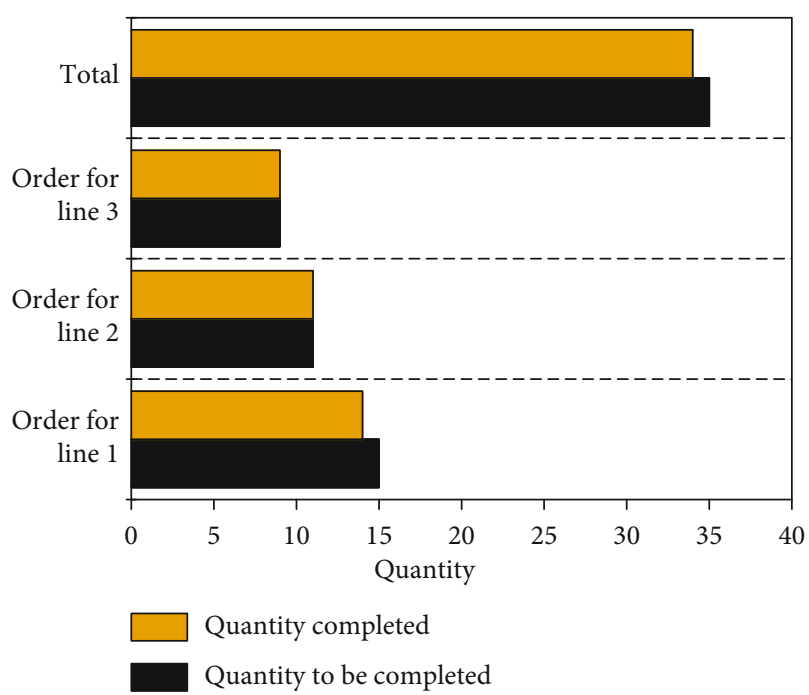

(a) Statistics of order completion

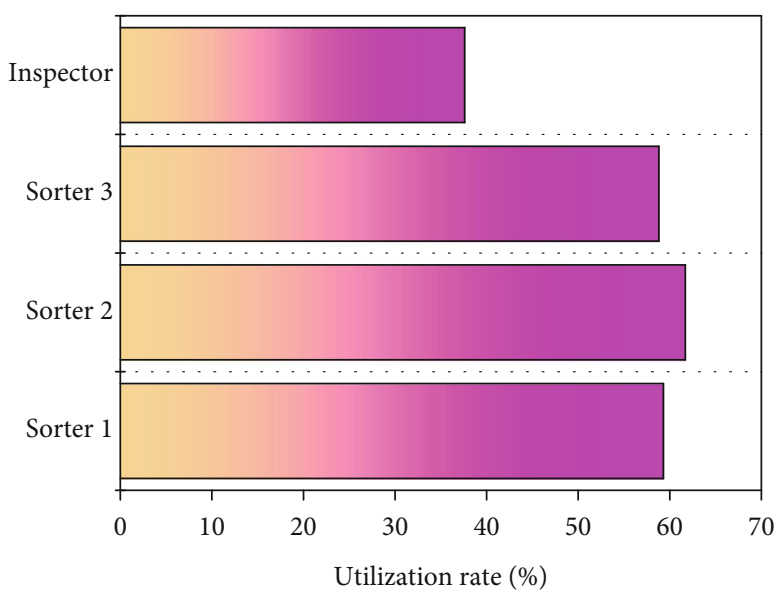

(b) Resource utilization of delivery process

FIGURE 6: Comparative analysis of picking list completion.

The system architecture diagram of the high-density three-dimensional internet of things landscape visualization control system is shown in Figure 3. The system mainly includes user management terminal, cloud platform, intelligent gateway, and landscape visualization system. Among them, the original landscape visualization system architecture is mainly composed of a main controller and a subcontroller [19]. A main controller has two RJ45 network ports, one is used as an input network port to communicate with higher-level management equipment, and the other is used as an output network port to realize cascade connection with subcontrollers [20,21]. Use the gateway device to communicate with the main controller of the original landscape visualization system, and use the gateway device to connect the landscape visualization system to the cloud platform for networking and unified management [22].

6.2. Optimization of Outbound Operation Process. The delivery process of the company is complex, and the warehouse supervisor needs to accept the order. It also requires a lot of manpower to divide several goods. At the same time, there will be many outbound orders and complex types of goods on the order [23]. However, the issue quantity of a single order is small, which increases the difficulty of goods sorting. In addition, due to the inaccurate inventory information of the company, the staff need to constantly modify the shipment quantity on the order during goods sorting, which further increases the difficulty of delivery [21].

After using RFID technology, RFID warehouse management system ensures the accuracy of inventory information. After the customer's order arrives, the order processing can be carried out in time, and the staff no longer need to use the barcode reader to read the barcode on the goods and modify the delivery order repeatedly. RFID warehouse management system can accurately assign delivery vehicles when goods leave the warehouse [24]. The information sharing between goods and vehicles is high, and the efficiency of goods ex warehouse is improved. Before leaving the warehouse, the following preparations need to be made: RFID electronic tags need to be pasted on the pallet; RFID fixed readers need to be installed at the warehouse exit and the entrance of the delivery area; warehouse staff need to be equipped with handheld RFID readers [25]. At the same time, company needs to provide customers with pallets, unloading workers and pick-up drivers pasted with RFID electronic tags, and provide customers with one-stop service for cargo transportation, so that RFID technology can be effectively applied to the downstream of the supply chain. The outbound operation flow optimized by RFID is shown in Figure 4.

\section{Results and Analysis}

After the introduction of RFID technology, the warehousing and outbound operation processes of cross-border ecommerce enterprises are simulated, and the improvement degree of warehousing process after the application of RFID technology is evaluated through the simulation data. At the same time, through the analysis of simulation results, the warehousing operation processes of cross-border ecommerce enterprises are further optimized to give full play to the advantages of RFID technology. The purpose of warehousing process simulation of cross-border e-commerce enterprises is very clear, that is, to evaluate the improvement of warehousing process by RFID technology by analysing the simulation data of warehousing and outbound links after quoting RFID technology.

7.1. Analysis of Simulation Results of Warehousing Process. After RFID technology is applied, the simulation and operation statistical results of warehousing process are shown in Figure 5.

Figure 5(a) shows the waiting time of goods in storage after RFID application. Compared with the previous waiting 


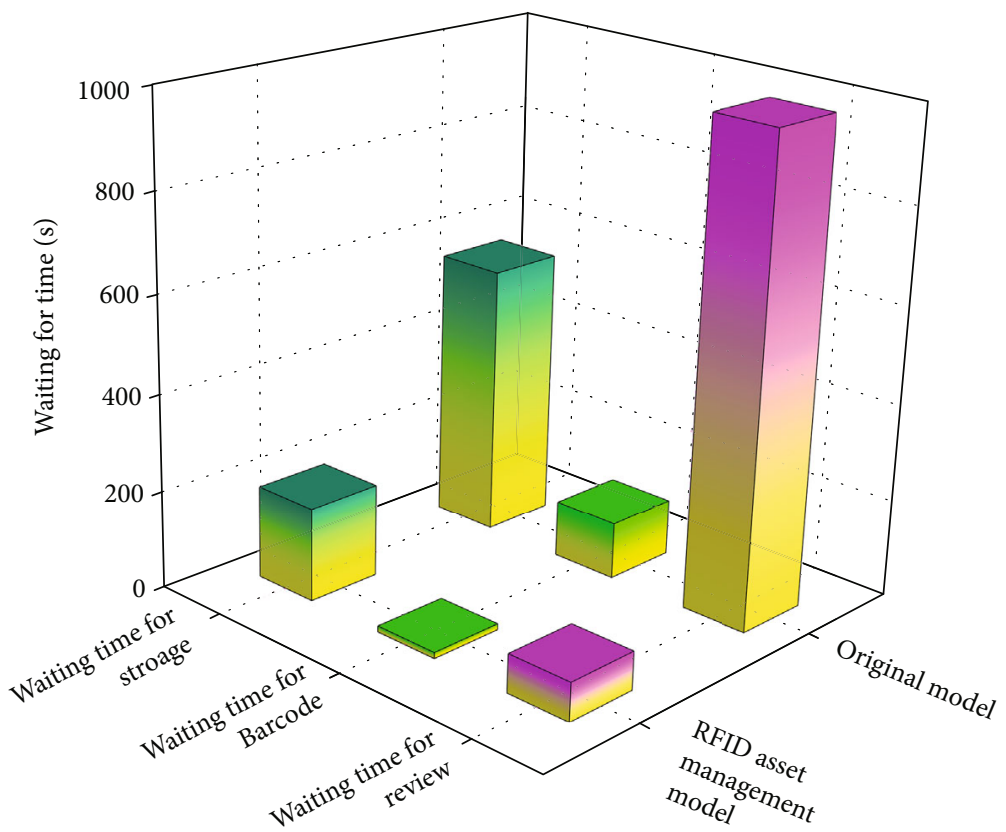

(a) Comparison of average waiting time

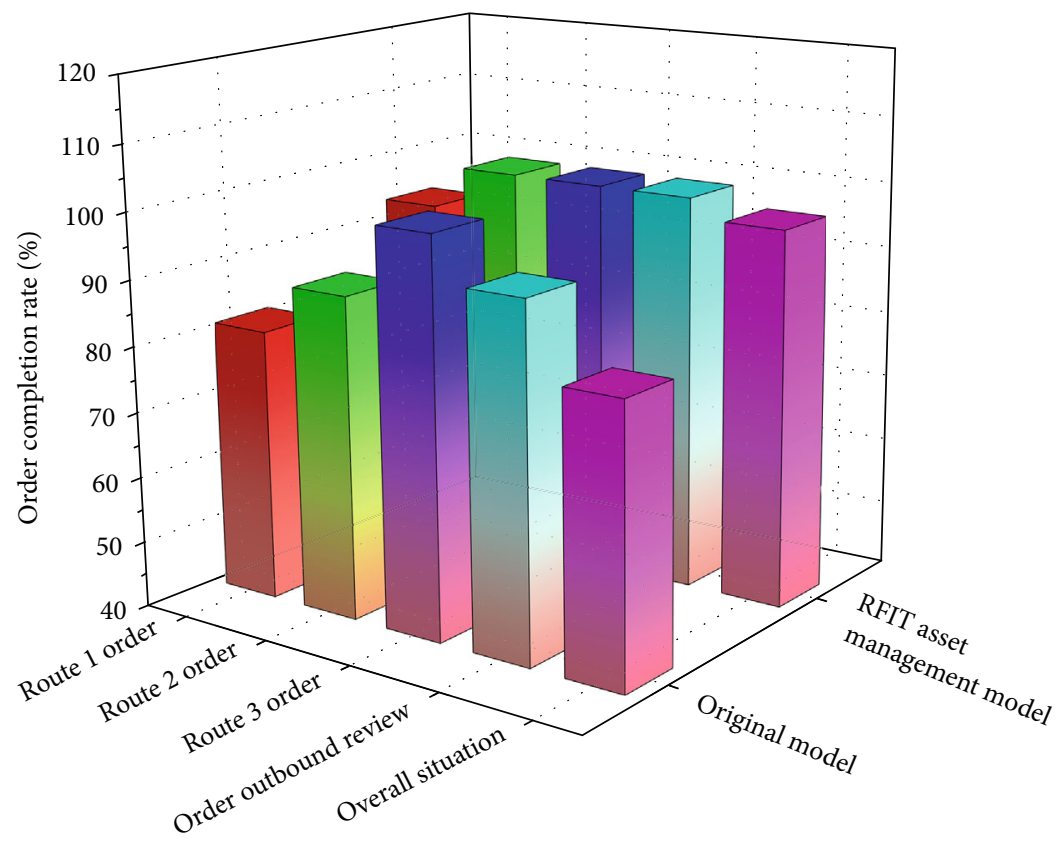

(b) Comparison of order completion rate

Figure 7: Comparison of order fulfilment.

time of goods in storage, it is found that the storage time of goods in storage after RFID application is greatly reduced from 556.7 seconds to 192.8 seconds, that is, it takes about 3 minutes to complete the storage. It can be seen that the application of RFID technology can effectively alleviate the warehousing pressure of goods. Figure 5(b) shows the utilization rate of employees and equipment in the warehousing process of cross-border e-commerce enterprises after applying RFID technology. It can be clearly found that the utilization rate of employees has decreased a lot. The utilization rate of inspectors decreased from about $90 \%$ to about $23 \%$, the work efficiency of tallyman's decreased more, from $89.5 \%$ to $18.5 \%$, and the utilization rate of forklifts remained at about $80 \%$. The reasons for this result are after the application of RFID technology, and the acceptance personnel and tallyman do not need to scan the goods one by one when reading the goods information. The application of RFID reader and writer equipment can read the information of one pallet of goods in 2 seconds, which greatly improves the work efficiency of the staff; the reason why the utilization 


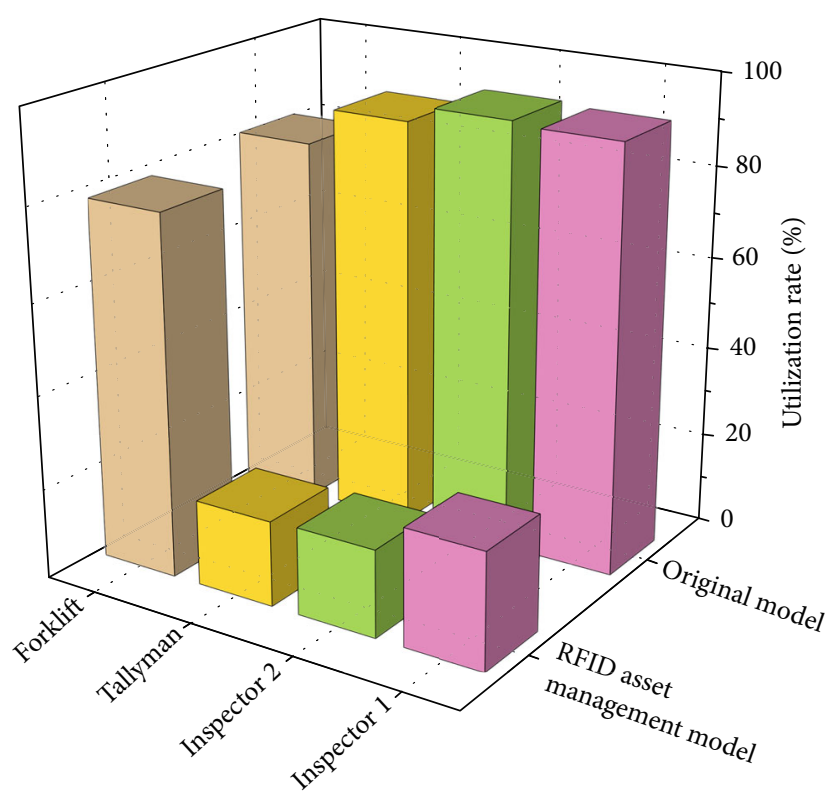

(a) Utilization rate of employees and equipment in warehousing phase

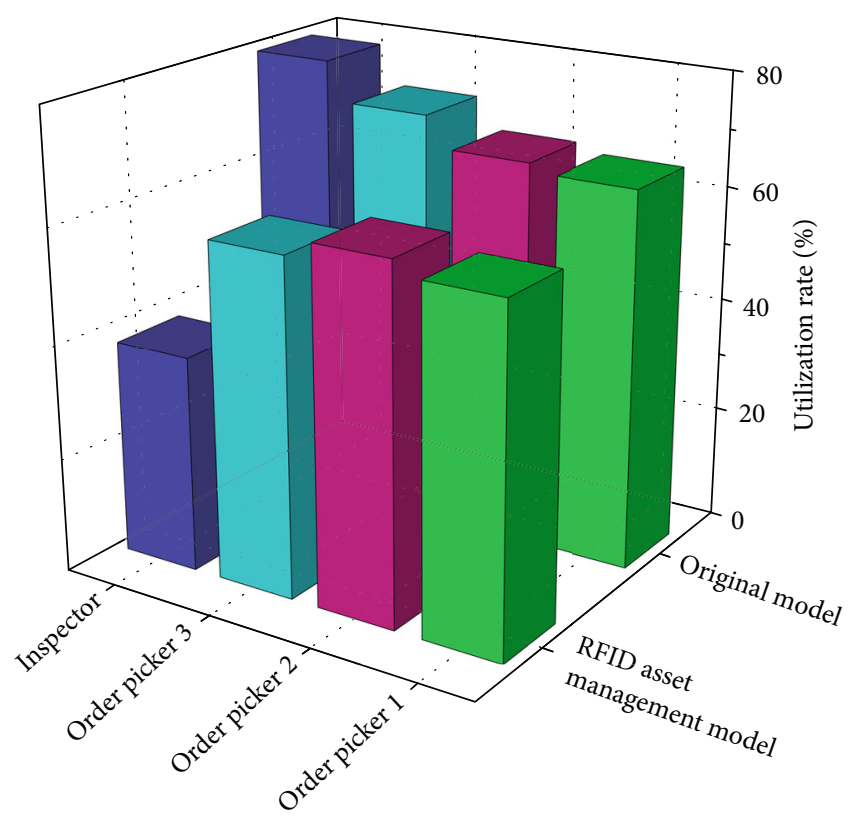

(b) Utilization rate of employees and equipment in the issue phase

FIGURE 8: Utilization rate of employees and equipment in the warehousing phase.

rate of forklift remains unchanged is easy to understand. The quantity of goods arriving and the working state of forklift remain unchanged, so its working utilization rate remains unchanged. The utilization rate of acceptance personnel drops below $25 \%$, indicating that they are idle for more than $75 \%$ of the time. Too much idle time of acceptance personnel will cause a waste of human resources. The warehousing of cross-border e-commerce enterprises can be adjusted appropriately, and only one inspector can complete the acceptance work, which not only ensures the smooth completion of the acceptance work but also reduces the labour cost.

7.2. Analysis of Simulation Results of Outbound Process. After RFID is applied, the completion of picking list in the warehousing and delivery process of cross-border ecommerce enterprises is shown in Figure 6.

With the application of RFID technology, inspectors recheck the delivery of goods through RFID readers, and the efficiency has been greatly improved. The average waiting time for goods recheck has been reduced from $987.3 \mathrm{sec}-$ onds to 78.9 seconds. In the past, goods that were sorted had to wait 16 minutes to receive recheck, but now it only takes one and a half minutes. The inspector's work efficiency has been improved, and the bottleneck problem in the delivery link has been solved. At the same time, the completion of orders has also been improved. 27 of the previous 33 orders have been completed, while 34 of the current 35 orders have been completed. Although not $100 \%$ completed, considering the discrete randomness of order arrival, the completion situation is also very optimistic.

7.3. Comparative Analysis of RFID Process and Traditional Process. Compare the two models before and after the appli- cation of RFID technology from the aspects of goods waiting time, order completion, and employee equipment utilization, so as to highlight the technical advantages of RFID. The average waiting time and order completion of goods in the warehousing process are shown in Figure 7.

As can be seen from Figure 7(a), the waiting time of the three links is shortened to varying degrees after the application of RFID technology. The waiting time for goods warehousing has decreased from 556.7 seconds to 192.8 seconds, indicating that the speed of goods warehousing has been more than doubled after the application of RFID technology; the application of RFID technology eliminates the need to paste bar codes on goods one by one, simplifies the goods warehousing process, and shortens the goods warehousing time; the waiting time for recheck of goods out of the warehouse changed the most, from 987.3 seconds to 78.9 seconds, which shortened the waiting time by ten times and improved the delivery speed. After the application of RFID technology, the work efficiency of each link in warehouse management can be improved, which not only reduces the waiting time between links but also saves the buffer space. As can be seen from Figure 7(b), the completion rate of order picking is improved to varying degrees after the application of RFID technology. After the RFID system is applied, the picking personnel can obtain the accurate outbound quantity and storage location of goods through the RFID system when they get the order, and the picking efficiency can be improved. In addition, the inspectors recheck the outbound goods through the RFID reader, which not only shortens the recheck time but also ensures the correctness of the recheck, which is the reason for the improvement of the order completion rate. The utilization rate of employees and equipment in the issue/receipt phase is shown in Figure 8. 


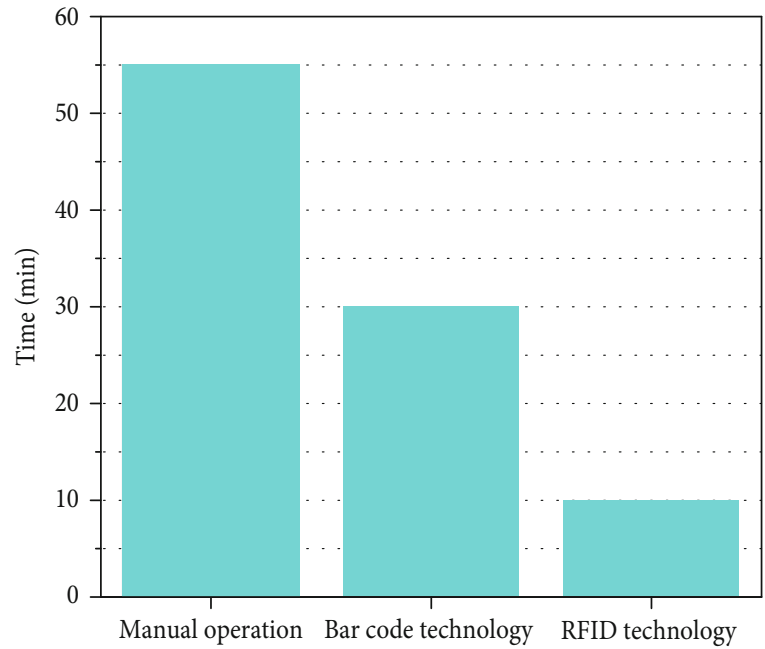

(a) Comparative analysis is of data acquisition and prediction

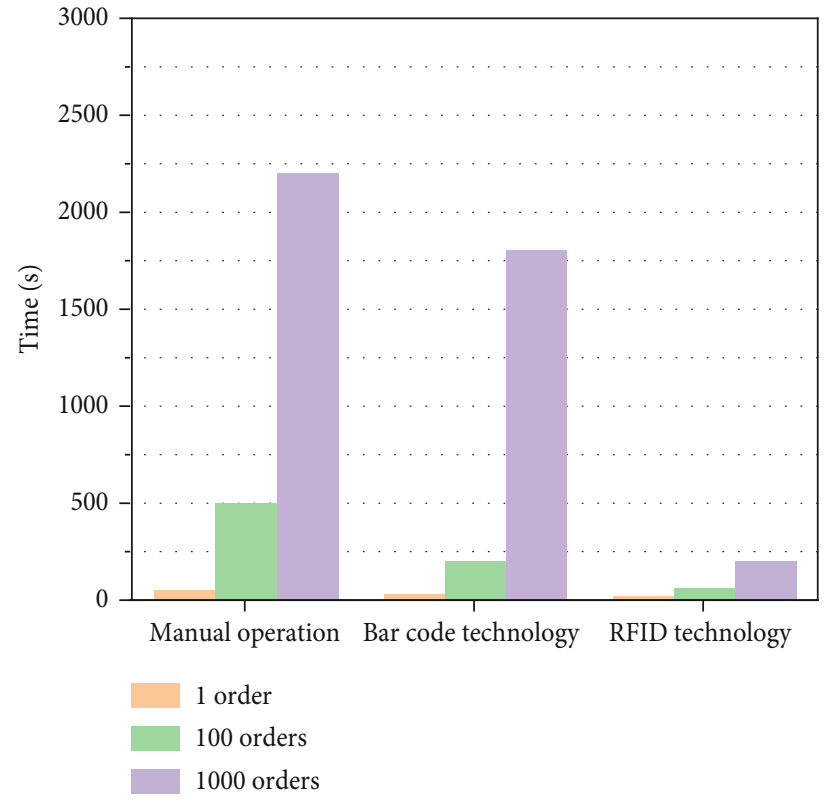

(b) Efficiency analysis of warehousing process

FIgURE 9: Comparative analysis of process optimization efficiency.

As can be seen from Figure 8, before and after the application of RFID technology, the utilization rate of employees and equipment in warehousing and outbound links decreased. In the warehousing link, RFID technology replaces the bar code, simplifies the warehousing process, and cancels the operations without added value, such as the process of information entry clerk entering cargo information and pasting bar code, which reduces the work intensity of employees and ensures the accuracy of data. In the outbound link, RFID system can effectively improve the work efficiency of sorting personnel and inspectors and reduce their work intensity. After the utilization rate of employees is reduced to varying degrees, the staffing may not be reasonable and can be adjusted appropriately. By comparing and analysing the simulation results of the two models, it can be found that RFID technology helps to improve the warehouse management level and service ability of cross-border e-commerce enterprises. After the application of RFID technology, the warehousing operation efficiency of cross-border e-commerce enterprises has been improved, and the employee utilization rate has decreased, indicating that the overall maximum throughput of the warehouse still has room to rise.

7.4. Comparative Analysis on Efficiency of Warehouse Management Process Optimization. After the application of RFID technology in the company's warehouse management system, the overall operation efficiency of the warehouse will be greatly improved. We can predict and compare the overall operation efficiency of the warehouse through the above optimization scheme design. It is mainly predicted from three aspects: data acquisition, warehousing process operation efficiency, and warehousing business process operation time, so as to prove the optimization effect of RFID technol- ogy. After the actual investigation of the company and the simulation of RFID technology data acquisition time, the prediction and comparative analysis of storage data acquisition are obtained, as shown in Figure 9(a). The picking speed of company orders and goods will directly affect the efficiency of warehousing operation. Here, a certain number of orders and goods are simulated. According to the actual storage situation and operation process, the operation consumption time of the company's manual operation, bar code scanning, and RFID technology is simulated and compared, as shown in Figure 9(b).

As can be seen from Figure 9(a), in terms of data acquisition, RFID technology takes less time than the original manual input and bar code technology of the company, which significantly improves the optimization effect of data acquisition. In terms of the operational efficiency of warehousing, the time-consuming warehousing using RFID technology is the least, as shown in Figure 9(b). The more orders and goods are handled, the more obvious the advantages of RFID technology, it can save about one-tenth of the time compared with the traditional bar code technology. At the same time, it can also save a lot of manpower and reduce the labour cost.

\section{Conclusion}

This paper analyses the construction of RFID technology in logistics warehouse management system, expounds the specific composition and function of RFID module in logistics warehouse management system, and analyses the application significance and function of RFID hardware equipment in logistics warehouse management system, so as to clarify the application advantages of RFID technology in logistics warehouse management system, and the specific application 
of RFID technology in logistics warehouse management is discussed. In short, the application of RFID technology not only makes the warehouse management more convenient but also greatly improves the overall level of logistics management, effectively reduces the logistics management cost, and greatly promotes the self-development and comprehensive strength of logistics enterprises. Aiming at improving the warehousing management efficiency of cross-border ecommerce enterprises, this paper realizes the warehousing process transformation by introducing RFID technology and uses the process simulation method to evaluate the process transformation results. In the next step, we will make a quantitative analysis of the data arising from the application of RFID technology and conduct an in-depth study on the software of RFID system.

\section{Data Availability}

The data used to support the findings of this study are available from the corresponding author upon request.

\section{Conflicts of Interest}

The authors declare that they have no known competing financial interests or personal relationships that could have appeared to influence the work reported in this paper.

\section{Acknowledgments}

This work was supported by the 13th Five-Year Plan of Education Science in Jiangsu Province in 2020 (Project Name: Research on Teaching Practice of "Advanced Diversion" of Cross-Border E-Commerce Talent Training in Higher Vocational Colleges under the Guidance of "Dual Needs" of Students and Enterprises, Project no.: D/2020/03/14).

\section{References}

[1] Y. Ling-Li, "Application of RFID technology in warehouse management of SMS cross border e-businesses: in the case of Zhejiang," Logistics Technology, vol. 35, no. 8, pp. 122-125, 2016.

[2] X. Zhu-Ni and H. Cheng-Li, "Application of RFID in intelligent warehousing and logistics," Electronic Technology and Software Engineering, vol. 11, no. 3, pp. 177-178, 2021.

[3] M. Yi-Jun, "Research on the application of RFID technology in logistics warehousing," China Business Theory, vol. 15, no. 3, pp. 34-35, 2020.

[4] P. Chun-Ning, "Research on the application of simulation technology in warehouse management," Modern Marketing, vol. 12, no. 4, pp. 204-205, 2020.

[5] W. Jia-Qi, “Application of RFID technology in warehouse management," Logistics Technology, vol. 43, no. 4, pp. 161163, 2020.

[6] L. Hai, "Application of RFID technology in intelligent storage," Modern Industrial Economy and Informatization, vol. 10, no. 3, pp. 50-51, 2020.

[7] S. Lei, "Application analysis and prospect of internet of things technology in warehousing and logistics," Communication World, vol. 27, no. 1, pp. 155-156, 2020.
[8] S. Guo-Qing, "Application analysis of internet of things technology in warehousing and logistics," Value Engineering, vol. 38, no. 35, pp. 258-259, 2019.

[9] Y. Lei, Z. Ling, and W. Rui, "Application of RFID technology in logistics warehousing," China New Communications, vol. 21, no. 4, pp. 101-103, 2019.

[10] Z. Yong-Quang, Z. Xin-Tong, and L. Bao, "Exploring the application of RFID technology in warehouse management process," Logistics Engineering and Management, vol. 40, no. 12, pp. 76-78, 2018.

[11] J. Li-Fang, "Application of UHF RFID technology in warehouse management," Modern Information Technology, vol. 2, no. 11, pp. 191-193, 2018.

[12] L. Xiu-Min, "Research on the application of RFID based internet of things technology in intelligent storage," Journal of Shangqiu Vocational and Technical College, vol. 17, no. 4, pp. 85-88, 2018.

[13] F. Ren-Yu, "Application of radio frequency identification technology in warehouse management system," Petrochemical Technology and Economy, vol. 34, no. 3, pp. 14-16, 2018.

[14] Z. Jing, "Discussion on the application of RFID technology in warehouse management in the logistics laboratory of Shenzhen institute of technology," Educational Modernization, vol. 4, no. 51, pp. 345-346, 2017.

[15] C. Meng-Ke and Y. Ling-Li, "Application of RFID technology in warehousing of cross-border e-commerce enterprises," Logistics Engineering and Management, vol. 39, no. 2, pp. 59-60, 2017.

[16] W. Yong-Qiang, "Research on the application of RFID technology in intelligent storage," Modern Industrial Economy and Informatization, vol. 6, no. 18, pp. 84-85, 2016.

[17] W. Shou-Hai, "Application of RFID in heavy truck logistics warehouse management," Logistics Technology, vol. 39, no. 8, pp. $144-148,2016$.

[18] D. Shan-Chao, "Application of RFID and UAV in warehouse management informatization," China New Communications, vol. 18, no. 8, pp. 45-46, 2016.

[19] X. Shou-Kun, Z. Zhong-Peng, and L. Yin-Qi, "Research on the application of RFID positioning technology in warehouse management," Value Engineering, vol. 35, no. 5, pp. 97-99, 2016.

[20] C. Jie and L. Ming-Kai, "Research on the application of RFID in warehouse management," Science and Technology Outlook, vol. 25, no. 13, pp. 172-173, 2015.

[21] Z. Xin, "Warehouse management informatization and application of RFID indoor positioning technology," China Market, vol. 11, no. 6, pp. 211-212, 2017.

[22] C. Si-Yu and B. Lu-Lu, "Research on the application of RFID technology in intelligent storage," China High Tech Enterprise, vol. 12, no. 5, pp. 76-77, 2017.

[23] W. Xiao-Zhou and G. Xi-Bin, "Research on the application of RFID technology in warehouse management," Wireless Internet Technology, vol. 17, no. 5, pp. 21-22, 2016.

[24] A. Mohammed, W. Qiang, S. Alyahya, and N. Bennett, "Design and optimization of an RFID-enabled automated warehousing system under uncertainties: a multi-criterion fuzzy programming approach," The International Journal of Advanced Manufacturing Technology, vol. 91, no. 5-8, pp. 1661-1670, 2017.

[25] H. Kai-Ming, "Research on the application of RFID radio frequency technology in warehouse logistics management," Electronic Technology and Software Engineering, vol. 16, no. 7, pp. 46-49, 2015. 